\title{
Curso de Pedagogia, organizações multilaterais e o superprofessor
}

\section{Undergraduate Education Program, multilateral organizations and super-teacher}

\author{
Olinda Evangelista ${ }^{1}$ \\ Jocemara Triches ${ }^{2}$
}

\begin{abstract}
RESUMO
No presente artigo objetivou-se discutir a relação entre as Diretrizes Curriculares Nacionais para o Curso de Pedagogia, aprovadas em 2006, e as orientações de Organizações Multilaterais. Analisou-se a documentação relativa à formação de professores procedente de Organizações Multilaterais, a literatura sobre reconversão docente e cotejaram-se os dados com os recolhidos nas DCNP. Foi possível verificar, por meio de análise qualitativa, que o professor assume um lugar privilegiado, constituindo-se como protagonista da reforma deflagrada, após os anos de 1990, na América Latina e Caribe. Implicitamente esse sujeito configura-se como um superprofessor-multifuncional, polivalente, flexível, protagonista, tolerante. A proposta de transformação de suas funções configura-se como estratégia de reconversão e confirma-se na documentação examinada. Inúmeros elementos das DCNP convergem com os propostos por OM. Tal articulação corrobora com o processo de alargamento do conceito de docência e gestão e a restrição da formação teórica e do tempo de formação que, por consequência, pode levar à desintelectualização do professor e à configuração do Curso de Pedagogia, segundo as DCNP, como espaço de reconversão do professor em superprofessor.
\end{abstract}

Palavras-chave: política educacional - 2000; Curso de Pedagogia; organizações multilaterais; reconversão docente; formação docente.

1 Doutora em Educação pela PUC/SP. Professora da Universidade Federal de Santa Catarina (UFSC), Centro de Ciências da Educação, Curso de Pedagogia e Pós-graduação em Educação da Universidade Federal de Santa Catarina (PPGE/UFSC), Brasil. E-mail: olindaevangelista35@ hotmail.com

2 Doutoranda em Educação no PPGE/UFSC. Professora no Departamento de Pedagogia, Centro de Ciências da Educação da Universidade do Estado de Santa Catarina (FAED/UDESC). Membro do Grupo de Estudos sobre Política Educacional e Trabalho (GEPETO). Brasil. E-mail: jtriches@yahoo.com.br 


\begin{abstract}
The purpose of this article is to discuss the relationship between the Brazilian National Curriculum Guidelines for the Undergraduate Education Program (DCNP) adopted in 2006, and the orientation from the Multilateral Organizations. It analyzed the documentation concerning the teachers training from Multilateral Organizations, and the literature in teacher reconversion comparing these data with those collected from the National Curriculum Guidelines. Through qualitative analysis, it was verified that the teacher assumes a privileged place, becoming protagonist of the reform triggered after 1990 across Latin America and the Caribbean. In an implicit way, this professional sets up like a super-teacher - a person who is multifunctional, polyvalent, flexible, protagonist, and tolerant. The proposal regarding the transformation of its functions appears as a reconversion strategy, and is confirmed in the documentation examined. Several elements from the Curriculum Guidelines converge with those proposed by Multilateral Organizations. This articulation corroborates with the expansion process of teaching and management concepts, and the restriction of theoretical training and of training time. Therefore, it may lead to the disintellectualization of the teacher, and according to the Curriculum Guidelines, to the configuration of the Undergraduate Education Program as space of the teacher's reconversion in super-teacher.
\end{abstract}

Keywords: educacional policy - 2000; Undergraduate Education Program; multilateral organizations; teaching reconversion; teacher training.

\title{
Introdução
}

O presente artigo resulta de uma investigação acerca da presença de diretrizes oriundas de Organizações Multilaterais $(\mathrm{OM})$ na definição das Diretrizes Curriculares Nacionais para o Curso de Pedagogia (DCNP), efetivadas pela Resolução CNE/CP n. 1, de 15 de maio de 2006 (BRASIL, 2006), e o professor proposto - denominado aqui superprofessor.

As mudanças recentes no Curso de Pedagogia $(\mathrm{CPe})$ fazem parte de um conjunto de reformas do Estado, iniciado nos anos de 1990, cujo objetivo foi o de adaptar a Educação às novas demandas da sociedade capitalista em base neoliberal. Tais mudanças articulam-se aos interesses do capital tendo em vista manter a ordem, o controle social e a hegemonia burguesa (MÉSZÁROS, 2005), âmbito em que a educação "é entendida como essencial à conservação das rela- 
ções sociais capitalistas contemporâneas por conjugar a conformação política e econômica das futuras gerações" (FALLEIROS; PRONKO; OLIVEIRA, 2010, p. 89). Nas palavras de Gomes (2006, p. 42): "é necessário ao capital escravizar a educação aos seus interesses, pois ela é um vetor estratégico de concretização da dominação, da exploração ou da emancipação humana".

O compartilhamento de uma agenda educacional entre países e OM gerou o fenômeno da universalização e da homogeneização de políticas educacionais, dos anos de 1990 para cá, principalmente nos países periféricos. O discurso hegemônico de OM associado aos interesses dos Estados é difundido via mídia, intelectuais, meio acadêmico, organizações não governamentais, entre outras formas. Por esses meios, pretende-se produzir consenso em torno de diretrizes, supondo-se sua implementação segundo as condições de cada Estado. Destaque-se que não se trata de uma mera adesão, mas de uma articulação entre interesses capitalistas, a despeito das posições diferentes ocupadas na divisão internacional do trabalho. Neves (2010) afirmam estar em jogo uma "nova pedagogia da hegemonia", "uma educação para o consenso sobre os sentidos de democracia, cidadania, ética e participação adequados aos interesses privados do grande capital nacional e internacional" para que o capitalismo permaneça hegemônico (NEVES, 2005a, p. 15).

Trata-se de uma política de formação que propõe operar a "reconversão docente" (EVANGELISTA, 2006, 2009, 2010a, 2010b) cujo sentido é o de favorecer a incorporação do projeto de formação de professores defendido por $\mathrm{OM}$, Estados nacionais e intelectuais orgânicos a eles ligados. O termo reconversão profissional surge no Brasil em meados dos anos de 1990 no campo extraeducacional (EVANGELISTA, 2010a). O fenômeno da "reconversão da formação docente é importante estratégia de produção de consenso para a reestruturação produtiva atual e para a criação de uma racionalização que coloca na educação, ou na falta dela, a responsabilidade pelas mazelas sociais" (EVANGELISTA, 2010a, p. 19). Desse modo, a educação e o Curso de Pedagogia só podem ser analisados nesse campo conflituoso, permeado pelos mais diferentes interesses.

As questões levantadas para debate neste artigo derivam da análise de documentos de política educacional, especialmente, de formação de professores, oriundos de OM, de seus intelectuais e do Estado. Examinamos a Resolução $C N E / C P$ n. 1/2006 (BRASIL, 2006) e 38 documentos vinculados à UNESCO, à $\mathrm{OEI}$ e ao $\mathrm{PREAL}^{3}$, datados de 1996 a 2008. Evidenciamos a relação entre as DCNP e a documentação de OM analisadas quanto à gestão e pesquisa; à

3 Neste artigo citaremos os documentos relativos às DCNP. Para aprofundamento cf. Triches (2010). 
denominação do profissional e ao alargamento do conceito de docência que constitui, entre outros pontos, o Superprofessor.

\section{Gestão educacional e pesquisa nas diretrizes do Curso de Pedagogia}

A gestão representa um dos elementos de consenso entre os intelectuais de $\mathrm{OM}$ e fortemente presente nas DCNP. O Artigo $4^{\circ}$, Parágrafo único, da Resolução $C N E / C P$ n. 1/2006 (BRASIL, 2006, p. 2), reza que:

Parágrafo único. As atividades docentes também compreendem participação na organização e gestão de sistemas e instituições de ensino, englobando:

I - planejamento, execução, coordenação, acompanhamento e avaliação de tarefas próprias do setor da Educação;

II - planejamento, execução, coordenação, acompanhamento e avaliação de projetos e experiências educativas não escolares;

III - produção e difusão do conhecimento científico-tecnológico do campo educacional, em contextos escolares e não escolares.

No Artigo $5^{\circ}$ (BRASIL, 2006, p. 3) a gestão é tratada como competência do professor que deve: desenvolver trabalho em equipe; manter diálogo; "participar da gestão das instituições contribuindo para elaboração, implementação, coordenação, acompanhamento e avaliação do projeto pedagógico"; "participar da gestão das instituições planejando, executando, acompanhando e avaliando projetos e programas educacionais, em ambientes escolares e não escolares". Nesse mesmo artigo, no interior das tarefas de gestão, temos as atividades relativas à pesquisa que deverá versar sobre aluno, escola, processo ensino-aprendizagem e propostas curriculares, ou seja, sobre todos os tipos de problemas e dificuldades que surgirem dentro da escola.

No Artigo $7^{\circ}$ (BRASIL, 2006, p. 5), a gestão aparece como um campo de estágio para os acadêmicos: "IV - [...] e) na participação em atividades da gestão de processos educativos, no planejamento, implementação, coordenação, acompanhamento e avaliação de atividades e projetos educativos; [...]". Ademais, é explicitada como gestão de "processos educativos", gestão de "sistemas e instituições de ensino", "gestão democrática" e "gestão e avaliação de projetos educacionais" (BRASIL, 2006, p. 2-4), além das tarefas de pesquisa voltadas à escola. À gestão educacional se associam as seguintes palavras: gestão, planeja- 
mento, participação, prática, execução, aplicação, acompanhamento, avaliação, competência, pesquisa, equipe e grupo. Essas expressões compõem as tarefas do gestor a ser formado no CPe.

Libâneo (2006, p. 845) chama atenção para os excertos citados, pois nota-se que "[...] Não está claro se cabe ao curso apenas propiciar competências para o professor participar da organização e da gestão ou prepará-lo para assumir funções na gestão e organização da escola". Para o autor (LIBÂNEO, 2006, p. 845), "as imprecisões conceituais resultam em definições operacionais muito confusas para a atividade profissional do pedagogo". Ademais, essas imprecisões e ampliações são os motivos que nos levam a discutir o processo de alargamento do conceito de docência e a reconversão do professor em superprofessor - muitas tarefas somadas à formação precária.

Na documentação internacional, a gestão é posta como parte da função do professor por vários intelectuais e agências, destacando-se Torres (1996), UNESCO (2000), Bomeny (2000), Rego e Mello (2002), Robalino Campos (apud UNESCO; CONSED, 2007), Tedesco e Fanfani (2002), UNESCO, OEA e MERCOSUL (2003), Uribe (2005). Robalino Campos (apud UNESCO; CONSED, 2007, p. 17), ao descrever o que considera ser o docente frente às novas competências dele exigidas, inclui a gestão, bem como o sentido de protagonista:

O que significa a profissão docente hoje? Ter profissionalismo e compromisso social, o que implica: (1) pensar e pensar-se como docentes não só ocupados com as tarefas didáticas, mas numa dimensão maior que inclui a gestão escolar e as políticas estratégicas educacionais; (2) ser protagonista das mudanças e capaz de participar e intervir nas decisões da escola e em espaços técnico-políticos mais amplos; (3) desenvolver capacidades e competências para trabalhar em cenários diversos, interculturais e em permanente mudança; (4) atuar com gerações que têm estilos e códigos de comunicação e aprendizagens diversos, com novas exigências e desafios à competência dos docentes.

Torres (1996, p. 55) afirma que a formação dos docentes "debe incluir el desarrollo de competencias tanto para la gestión pedagógica como para la gestión administrativa, partiendo de un concepto unificado de gestión escolar que incluye tanto el ambito administrativo como el pedagógico [...]". Assim, a gestão sofre uma ressignificação e ampliação; a questão pedagógica e o "próprio desenvolvimento profissional" também se tornam campo da gestão, pois se tem em vista os resultados e a responsabilização por eles. Tal proposição fica mais 
elucidada no excerto do documento da $\operatorname{UNESCO}$ (2000, p. 58): "La planificación de largo plazo, la participación de diferentes actores, los consensos, y la responsabilidad y preocupación por los resultados son características centrales de los modelos de gestión en esta época".

As ideias acima foram complementadas e reiteradas por Tedesco e Fanfani (2002, p. 16): "Poco a poco se van perfilando nuevos modelos de organización y nuevos estilos de gestión que generan nuevas demandas a los agentes escolares". Afirma-se uma crise de identidade dos gestores e dos professores devido à nova demanda em torno da gestão - a participação de todos. Talvez seja esse um dos elementos que conduziu os intelectuais da área da educação no Brasil envolvidos com a formulação das DCNP a alterarem a denominação tradicional do profissional formado pelo $\mathrm{CPe}$, não Pedagogo, mas Licenciado. A palavra "pedagogo" sequer aparece na Resolução. Chama também atenção as citações - dez vezes - do tripé "planejamento-execução-avaliação", evidenciando-se o realce dado à prática do professor e ao controle dos resultados de seu trabalho sob a perspectiva da mensuração. $\mathrm{O}$ mesmo tripé consta de documento da UNESCO, OEA e Ministérios de Educação dos países do Mercosul (2003, p. 103): "la gestión escolar se refiere a las actividades de planificación, ejecución y evaluación que los directivos y profesores tienen que desarrollar para llevar adelante sus proyectos educativos y curriculares".

A gestão é colocada como estratégica, pois se entrelaça com responsabilização, resultados, cumprimento de metas, participação, inclusão, envolvimento e empreendedorismo - assim como numa empresa. Para Hostins $(2009$, p. 12) "nos documentos das políticas internacionais esse conceito responde bem aos critérios do gerenciamento da Educação e da racionalização dos sistemas em busca da gestão competente do conhecimento". O professor, além de todas as competências e funções descritas, precisa assumir a posição de líder. Segundo Uribe (2005) deve ser líder e administrar a escola, a aprendizagem e os problemas que nela surgirem. Tal abordagem vai ao encontro das defesas das OM acerca do protagonismo docente.

A avaliação é vista como elemento intrínseco à gestão. Nas DCNP, foi citada 14 vezes (BRASIL, 2006); na documentação de OM é indicada como competência do "novo" professor, que precisa ser profissionalizado no sentido de saber avaliar, julgar e ser autônomo, não se deixando pressionar por conflitos que constituem seu exercício profissional. De outro lado, Vieira (2007, p. 107) assinala que 
O conceito de gestão presente nas DCNP não significa formação do antes denominado 'especialista' de ensino, mas abarca todos os processos de gestão referidos à educação, o escolar, o familiar, o financeiro, o de conhecimento, o de alunos, entre outros. Este conceito supõe que não apenas o gestor strictu senso deve se ocupar da administração da escola, mas o próprio professor é tido como gestor.

Concluímos que nos documentos - DCNP e de OM - recomenda-se que o professor, seja como gestor ou participando da gestão, deve planejar, executar e avaliar. A gestão será administrativa, pedagógica e profissional. Shiroma e Evangelista (2004, p. 527) entendem que está em questão "precisamente a gestão da crise social pela construção do professor e da escola como 'gerentes' dessa mesma crise, conquanto, reafirme-se, esse seja um discurso destinado a construir a desejada aparência de 'poder do professor'". O objetivo é que os docentes (expressão usada predominantemente na documentação internacional) ou professores/licenciados/docentes formados no CPe (conforme a Resolução) se responsabilizem pelos processos e resultados escolares e gerenciem sua formação. Esse rol de exigências disseminado pela documentação estudada concretiza o processo de reconversão do professor em superprofessor, profissional com aparentes poderes e condições de responder a todas as demandas de seu trabalho.

Dessa forma, praticamente todas as atividades da escola e dos profissionais da educação tornam-se função do professor e campo da gestão - inclusive a pesquisa ${ }^{4}$. Esse encaminhamento conduz a um empobrecimento teórico, tanto pelo alargamento da função da docência quanto o da gestão. Ou seja, de um lado, alarga-se o espectro das tarefas docentes e da gestão, pois além de acoplá-las, adicionam-se outras demandas. De outro, como consequência, temos a restrição da concepção de docência em sentido estrito, gestão e pesquisa; a formação numa perspectiva prática e utilitarista e o encurtamento do tempo - não necessariamente em quantidade de meses - de formação em razão da quantidade de conteúdos que compõem o currículo do curso. Se colocada a pesquisa em prática como indica a Resolução (BRASIL, 2006) ou a documentação de OM se perderá um importante espaço de análise e crítica e de produção de conhecimento ou,

4 Relembramos que a Resolução CNE/CP n. 1/2006 (BRASIL, 2006, p. 2-3) menciona a pesquisa como parte da gestão: "Artigo $4^{\circ}$, Parágrafo único [...] III - produção e difusão do conhecimento científico-tecnológico do campo educacional, em contextos escolares e não escolares" e Artigo $5^{\circ}$ "XIV - realizar pesquisas que proporcionem conhecimentos, entre outros: sobre alunos e alunas e a realidade sociocultural em que estes desenvolvem suas experiências não escolares; sobre processos de ensinar e de aprender, em diferentes meios ambiental-ecológicos; sobre propostas curriculares; e sobre organização do trabalho educativo e práticas pedagógicas". 
ainda, um importante recurso que pode contribuir para "contrainternalização" da lógica capitalista (MÉSZÁROS, 2005, p. 56).

\section{Denominação profissional e alargamento do conceito de docência}

Nas DCNP o profissional formado no CPe é denominado Licenciado em Pedagogia, professor, docente, profissional da educação, além de "agente intercultural" (BRASIL, 2006, p. 1, 3, 6). Acrescente-se gestor. Não há as denominações de pedagogo, educador ou pesquisador. Outras ações que deve contemplar são: "atuar com ética", "compreender, cuidar e educar crianças", "fortalecer o desenvolvimento e as aprendizagens", "trabalhar, em espaços escolares e não escolares", "reconhecer e respeitar as manifestações e necessidades", "ensinar", "relacionar as linguagens dos meios de comunicação", "identificar problemas socioculturais e educacionais", "demonstrar consciência da diversidade", "desenvolver trabalho em equipe", "participar da gestão", "realizar pesquisas", "utilizar, com propriedade, instrumentos próprios para construção de conhecimentos pedagógicos e científicos" e "estudar, aplicar criticamente as diretrizes curriculares" (BRASIL, 2006, p. 2-3). Esse professor se parece com o ideal de "educador" promovido pela UNESCO (1996). Esse perfil de professor pode ser encontrado em Torres (2001, p. 7): “Un 'buen docente', dispuesto a aceptar para sí los desafíos de un nuevo rol, más profesional, creativo y autónomo, y a aprovechar las tecnologías tanto para la enseñanza como para su propio aprendizaje permanente" e em Verdugo (1996, p. 70): "un educador que ejerza un rol específico y estable en el tiempo dentro del sistema, pero que asimismo, esté preparado para enfrentar con flexibilidad la adaptación a nuevos $\mathrm{y}$ alternativos papeles y funciones profesionales".

A Resolução (BRASIL, 2006) representa um exemplo da perspectiva que tem caracterizado a reconversão profissional, especificadamente via alargamento do conceito de docência (EVANGELISTA, 2006, 2008, 2010a, 2010b), começando pela conclusão de que indicam que o profissional a ser formado é professor. A docência e a gestão como partes da formação do Licenciado em Pedagogia expressam o alargamento do conceito de docência (TRICHES, 2006, 2007; VIEIRA, 2007; EVANGELISTA, 2006, 2008, 2010a, 2010b); a reconversão docente (EVANGELISTA, 2006, 2009, 2010a, 2010b, 2010c; EVANGELISTA; TRICHES, 2008) e uma inespecífica denominação do formado no curso, convergindo para a ideia de superprofessor. Os elementos que nos levaram a fazer tais afirmações estão na própria Resolução e na documentação de OM, entre eles, em Tedesco e Fanfani (2002, p. 16-17): 
Su actividad [do docente] es cada día más relacionada y la polivalencia, la capacidad de tomar iniciativas y asumir responsabilidades, la evaluación, el trabajo en equipo, la comunicación, la resolución de conflictos, etc. se convierten en competencias estratégicas que definen su nuevo rol profesional [...].

Agregam os autores: "En verdad, la escuela es una institución multifuncional y cada vez se esperan más cosas de la escuela y los maestros" (TEDESCO; FANFANI, 2002, p. 19).

Shiroma e Evangelista (2004, p. 527) afirmam que essa tendência de alargamento inicia-se nos anos 1990, quando

a denominada competência docente é instada a extrapolar as fronteiras da sala de aula sem alçar vôo para além dos muros escolares. Nesse processo, de alargamento-restrição das atribuições docentes, verifica-se o fechamento do espectro político do professor que deve se preocupar apenas com o que diz respeito aos resultados de seu ensino e à sua atuação escolar, abstraindo-os das condições político-econômicas que os produzem, embora, contraditoriamente, essas mesmas condições abstraídas sejam chamadas para justificar a reforma de sua formação.

A noção de docência alargada e a perspectiva pragmática sugerem a constituição da docência como "ação", como prática profissional - não só de sala de aula - articulada a uma perspectiva de pesquisa vocacionada à resolução de problemas e pensados nos moldes da busca de "bons" resultados escolares. Predomina a ênfase no controle dos resultados, principalmente via lógica das competências (VAILLANT, 2003; REGO; MELLO; 2002; UNESCO; CONSED, 2007; UNESCO; PRELAC, 2004, 2007; UNESCO, 2006, 2002; TORRES, 1996, 1998, 2001; TEDESCO; FANFANI, 2002).

\section{Considerações finais}

Os procedimentos analíticos permitiram a percepção de um projeto de formação de professores por parte de OM que cobra desses profissionais um excesso de competências e responsabilidades. De outro lado, as DCNP pautam-se 
em dois eixos principais: docência - em sentido estrito - e gestão, nessa ordem de importância, cabendo à pesquisa um papel subsidiário à gestão. Ademais, a pesquisa, a avaliação, a responsabilização ${ }^{5}$ pelo processo educativo e resultados de aprendizagem e a autonomia são postas como componentes da gestão nas duas documentações, expressando a amplitude da gestão, assim como da docência.

É possível afirmar que o projeto de formação em andamento na América Latina e Caribe, e expresso na Resolução, caracteriza-se pelo alargamento do conceito de docência; responsabilização dos professores pela educação e por sua profissionalização, gestão da escola e de sua formação, uso da pesquisa como recurso da gestão para resolver desafios da prática profissional. Sua ênfase está na aprendizagem, nos conteúdos aplicáveis e úteis, nas competências, na educação inclusiva e na educação para a tolerância. Professores e alunos são objetos e, ao mesmo tempo, instrumentos dessa reforma, tendo em vista a constituição de um sujeito competente, flexível e adaptado aos ditames do modo de produção capitalista. Esse projeto expressa a "nova pedagogia da hegemonia" (NEVES, 2005b, 2010) que, ao fim, contribui ainda mais para a alienação dos sujeitos para que "em seus parâmetros estruturais fundamentais, o capital dev[a] permanecer sempre incontestável” (MÉSZÁROS, 2005, p. 27).

Essa trajetória possibilitou-nos formular a ideia de que a reconversão do professor configura-o como superprofessor. Nascido das "cinzas do professor tradicional" (EVANGELISTA, 2001), é posto como solução para os problemas da sociedade. Seu sentido é oferecido por um duplo papel: objeto da reforma, dado que ela atua modificando o papel do professor, e instrumento da reforma, posto que será por meio dele que a reforma será implementada. Ou seja, um movimento contraditório que mostra a relação existente entre o superprofessor e o professor-instrumento que, sendo objeto da reforma, é responsável por sua execução.

Essa lógica corrobora para a compreensão de que o superprofessor é reduzido a "sujeito culpabilizado por seus fracassos, assim como dos de seus alunos" (SHIROMA; EVANGELISTA, 2004, p. 537). Nesse sentido, ao se construir a noção de superprofessor e se teorizar acerca da sua condição de objeto-instrumento da reforma, simultaneamente, assinalamos que as estratégias desencadeadas por $\mathrm{OM}$ e incorporadas à produção nacional redundam em iniciativas que procuram suprimir o professor como sujeito histórico. Vale a pena, entretanto, considerar o alerta de Virgínia Fontes (2012, p. 30): “O reservatório transbordante de capitais e de energias reconvertidas não pode assegurar essa forma de política hoje hegemônica. A crise ronda".

5 Exemplo claro da responsabilização sobre o professor formado no CPe está no Artigo $5^{\circ}$ : "XVI - estudar, aplicar criticamente as diretrizes curriculares e outras determinações legais que lhe caiba implantar, executar, avaliar e encaminhar o resultado de sua avaliação às instâncias competentes" (BRASIL, 2006, p. 3). 


\section{REFERÊNCIAS}

BOMENY, Helena. O Seminário OREALC/UNESCO sobre o Futuro da Educação na América Latina e Caribe. Relatório de evento da UNESCO. RJ: Fundação Getulio Vargas; PREAL(BR), 2000. Disponível em: <http://www.schwartzman.org.br/simon/delphi/pdf/ seminario.pdf $>$. Acesso em: 10/02/2012.

BRASIL. Conselho Nacional de Educação. Resolução $C N E / C P$ n. 1, de 15 de maio de 2006. Institui Diretrizes Curriculares Nacionais para o Curso de Graduação em Pedagogia, licenciatura. 2006. Diário Oficial da União, Brasília, 16 mai. 2006, Seção 1, 11 p.

EVANGELISTA, Olinda. Almas em Disputa. Reconversão do docente pela ressignificação da educação. Projeto de pesquisa PQ/CNPq 2006-2010. Florianópolis: EED/CED/ UFSC, 2006 (mimeo).

. Conhecimento e Diretrizes curriculares para o curso de Pedagogia. Perspectiva, UFSC, v. 26, p. 551-570, 2008.

. Rede Kipus e reconversão docente na América Latina e Caribe. In: SEMINÁRIO NACIONAL ESTADO E POLÍTICAS SOCIAIS, 4., 2009. Anais... Cascavel PR: UNIOESTE, 2009. p. 1-14.

. Almas em Disputa: reconversão do docente pela ressignificação da educação. Relatório de pesquisa PQ/CNPq 2007-2010. Florianópolis: EED/UFSC, 2010a (mimeo).

. O Governo Lula e a política de formação docente. Projeto de Pesquisa PQ/ CNPq 2010-2013. Florianópolis: EED/UFSC, 2010b (mimeo).

. Política de formação docente no governo Lula (2002-2010). In: SEMINÁRIO INTERNACIONAL RED ESTRADO, 8., 2010. Anais...Lima/Peru: Universidad de Ciencias y Humanidades, 2010c. p. 1-14.

EVANGELISTA, Olinda; TRICHES, Jocemara. Reconversão, alargamento do trabalho docente e Curso de Pedagogia no Brasil. In: SEMINÁRIO REDESTRADO NUEVAS REGULACIONES EN AMÉRICA LATINA, 7., 2008. Anais... Buenos Aires: Agencia; UBA, 2008. (CD ROM).

FALLEIROS, Ialê; PRONKO, Marcela A.; OLIVEIRA, M ${ }^{\mathrm{a}}$ Teresa C. Fundamentos históricos da formação/atuação dos intelectuais da nova pedagogia da hegemonia. In: NEVES, Lúcia Ma W. (Org.). Direita para o Capital e Esquerda para o Social. Intelectuais da nova pedagogia da Hegemonia no Brasil. São Paulo: Xamã, 2010.

FONTES, Virginia. A humanidade se dilui no shopping. Caros Amigos, jul. 2012, p. 30.

GOMES, Valdemarin Coelho. Formação de professores no contexto da crise estrutural do capital. Dissertação (Mestrado em Educação) - PPGE, Universidade Estadual do Ceará, Fortaleza, 2006. 
HOSTINS, R. C. L. O ensino superior em tempos de crise do capital virtualizado e da individualização social pós-moderna: sua expressão nas diretrizes para o curso de pedagogia In: REUNIÃO ANUAL DA ANPED, 2009, Caxambu. Sociedade, cultura e Educação; novas regulações? Pernambuco: ANPED, 2009. Disponível em: <http://www.anped.org. $\mathrm{br} /$ reunioes/32ra/arquivos/trabalhos/GT11-5143--Int.pdf $>$. Acesso em: 30/9/12.

LIBÂNEO, José Carlos. Diretrizes curriculares da pedagogia: imprecisões teóricas e concepção estreita da formação profissional de educadores. Revista Educação e Sociedade, Campinas: CEDES, v. 27, n. 96, out. 2006, p. 843-876.

MÉSZÁROS, Istán. A educação para além do capital. São Paulo: Boitempo, 2005.

NEVES, Lúcia Ma . W. Apresentação. In: (Org.). A nova pedagogia da hegemonia. Estratégias do capital para educar o consenso. São Paulo: Xamã, 2005a.

. (Org.). A nova pedagogia da hegemonia. Estratégias do capital para educar o consenso. São Paulo: Xamã, 2005b. 312p.

. (Org.). Direita para o Capital e Esquerda para o Social. Intelectuais da nova pedagogia da Hegemonia no Brasil. São Paulo: Xamã, 2010. 223p.

REGO, Teresa C.; MELLO, Guiomar N. de. Formação de professores na América Latina e Caribe: a busca por inovação e eficiência. In: CONFERÊNCIA REGIONAL "O DESEMPENHO DOS PROFESSORES NA AMÉRICA LATINA E NO CARIBE: NOVAS PRIORIDADES", de 10 a 12 de julho de 2002, Brasília, Brasil: UNESCO; PREAL; BID; MEC, 2002. Disponível em: <www.namodemello.com.br/pdf/escritos/ oficio/ teresaversaoenviada.pdf $>$. Acesso em: 13/10/2009.

ROBALINO CAMPOS Magaly. Ator ou protagonista? Dilemas e responsabilidades sociais da profissão docente. Revista PRELAC, n. 1, junho 2005. Disponível em: <http:// unesdoc.unesco.org/ images/0014/001446/144666s.pdf $>$. Acesso em: 10/2/2010.

SHIROMA, Eneida O.; EVANGELISTA, Olinda. A colonização da utopia nos discursos sobre profissionalização docente. Revista Perspectiva, Florianópolis: NUP; UFSC, v. 22, n. 2, p.525-545, jul./dez., 2004.

TEDESCO, Juan Carlos; FANFANI, Emilio Tenti. Nuevos docentes y nuevos alumnos. In: CONFERÊNCIA REGIONAL "O DESEMPENHO DOS PROFESSORES NA AMÉRICA LATINA E NO CARIBE: NOVAS PRIORIDADES", de 10 a 12 de julho de 2002, Brasília, Brasil: UNESCO; PREAL; BID; MEC, 2002.

TORRES, Rosa Maria. Formación docente: clave de la reforma educativa. "Nuevas formas de aprender y enseñar", Santiago: UNESCO, 1996. Disponível em: <http:// www.fronesis.org $>$. Acesso em: 17/12/2009.

. Nuevo papel docente ¿Qué modelo de formación y para qué modelo educativo? In: SEMANA MONOGRÁFICA "APRENDER PARA EL FUTURO: NUEVO MARCO DE LA TAREA DOCENTE”, 13., Madrid, noviembre, 1998. 
. La profesion docente em la era de la informatica y la lucha contra la pobreza. Documento de apoyo. In: REUNIÓN DEL COMITÉ REGIONAL INTERGUBERNAMENTAL DEL PRELAC, 7., Santiago de Chile, agosto de 2000. Santiago: UNESCO, 2001.

TRICHES, Jocemara. Organizações multilaterais e curso de pedagogia: a construção de um consenso em torno da formação de professores. Dissertação (Mestrado em Educação) -Florianópolis, SC: PPGE/UFSC, 2010. 218p.

. O curso de Pedagogia: hegemonia da docência. Florianópolis: UFSC, 2006. Relatório final de pesquisa PIBIC/CNPq 2005-2006. (mimeo).

. O curso de Pedagogia: projetos em disputa. Florianópolis: UFSC, 2007. Relatório final pesquisa PIBIC/CNPq 2006-2007. (mimeo).

TRICHES, J.; EVANGELISTA, O. Curso de Pedagogia: espaço de reconversão do professor em superprofessor. In: SEMINÁRIO INTERNACIONAL DE LA RED ESTRADO, 9., 2012. Anais... Santiago, Chile. Políticas educativas para América Latina: praxis docente y transformación social. Santiago, Chile: UCH; CLACSO, 2012.

UNESCO. La profesion docente y el desarrollo de la educacion en America Latina y el Caribe. Boletim PRELAC, Chile: UNESCO, n. 41, dezembro, 1996.

UNESCO. Balance de los 20 años del Proyecto Principal de Educación para América Latina y el Caribe. In: REUNIÓN DEL COMITÉ REGIONAL INTERGUBERNAMENTAL DEL PRELAC, 7. Santiago de Chile, agosto de 2000.

UNESCO. Proyecto Principal de Educación para América Latina y el Caribe. In: REUNION INTERGUBERNAMENTAL DEL PRELAC, 1. Havana, Cuba, novembro, 2002. Disponível em: $<\mathrm{http}: / / \mathrm{www}$.unesco.cl/ port/prelac/focoest/2.act $>$. Acesso em: 14/1/2010.

UNESCO. Modelos innovadores en la formación inicial docente: una aposta por el cambio. Estudio de casos de modelos innovadores em la formación docente en América Latina y Europa. Chile: UNESCO, 2006. Disponível em: <http://unesdoc.unesco.org/ images/0014/ 001465/146544s.pdf $>$. Acesso em: 14/1/2010.

UNESCO; CONSED. O desafio da profissionalização docente no Brasil e na América Latina. São Paulo: UNESCO; MEC; CONSED, 2007. Disponível em: <http://unesdoc. unesco. org/images/0015/001501/150 121 por.pdf $>$. Acesso em: 14/1/2010.

UNESCO; OEA; MERCOSUL. Educar em la diversidad. Material de formación docente. Brasília: UNESCO; OEA; Ministérios de Educação dos países do MERCOSUL 2003. Disponível em: $<$ http://www.inclusioneducativa.org/content/documents/educar_diversidad. pdf $>$ Acesso em: 18/1/2010.

UNESCO; PRELAC. Projeto Regional de Educação para América Latina e Caribe: uma trajetória regional em direção à Educação para Todos. Revista PRELAC, Chile: UNESCO, ano 1, n. 0, 2004. Disponível em: <http://unesdoc.unesco.org/images/0013/001372/ 
137293por.pdf. $>$. Acesso em: 10/1/2010.

UNESCO; PRELAC. Educación de qualidad para todos: um asunto do direito humano. Documento de discusión sobre políticas educativas. In: REUNIÓN INTERGUBERNAMENTAL DEL PRELAC. 2. Santiago, Chile: UNESCO, 2007.

URIBE, Mario. A liderança docente na construção da cultura escolar de qualidade: um desafio de ordem superior. Revista PRELAC, n. 1, junho. 2005. Chile: UNESCO, 2005. Disponível em: $<$ http://unesdoc. unesco.org/images/0014/001446/144666s.pdf $>$. Acesso em: $10 / 2 / 2010$.

VAILLANT, Denise. Documento Formação de Formadores: Estado da Prática. In: PREAL n. 25. Outubro de 2003. Disponível em: $<$ http://www.oei.es/docentes/articulos/formacion_formadores_estado_practica_vaillant_portugues.pdf $>$. Acesso em: 12/02/2010.

VERDUGO, Osvaldo. La creciente importancia del docente en un mundo en cambio. Boletim PRELAC, n. 41, dezembro, 1996. Disponível em: <http://www.oei.es/na6005. $\mathrm{htm}>$. Acesso em: 10/10/2009.

VIEIRA, Suzane da R. Diretrizes Curriculares para o curso de Pedagogia: pedagogo, docente ou professor? Dissertação (Mestrado em Educação) - PPGE/CED, Universidade Federal de Santa Catarina, 2007.

Texto recebido em 02 de julho de 2012 .

Texto aprovado em 23 de setembro de 2012. 